\title{
UM BREVE COMENTÁRIO DE MEDARD BOSS SOBRE PSICOTERAPIA DE GRUPO: A TRANSFERÊNCIA NA SITUAÇÃO GRUPAL
}

\author{
A Brief Comment by Medard Boss about Group Psychotherapy: Transference in the group situation \\ Un Breve Comentario de Medard Boss sobre Psicoterapía de Grupo: La Transferencia en la \\ situación grupal
}

Paulo Evangelista

\begin{abstract}
Resumo: Em 1965, Medard Boss publica um livro baseado em suas viagens à Índia e à Indonésia na década anterior. Convidado como professor visitante de medicina, entra em contato com ocidentalização da medicina indiana, o que lhe fornece dados para refletir sobre as limitações do pensamento ocidental para a compreensão do ser humano, assim como considerar a possibilidade de entendimento da psicopatologia a partir da "ontologia" milenar indiana. No relato de viagem, tece breves considerações sobre grupos de psicoterapia coordenados por psiquiatras indianos. Neste artigo, apresentamos uma tradução dos dois parágrafos sobre psicoterapia de grupo, que são quase os únicos escritos por Boss ao longo de sua obra sobre o tema. Fiel à compreensão psicanalítica dos fenômenos psicoterapêuticos, da qual nunca quis se afastar, Boss interpreta os fenômenos grupais como transferência e resistência. Com isso, enfatiza a relação de cada participantes com o terapeuta do grupo, relegando a segundo plano outros fenômenos grupais.
\end{abstract}

Palavras-chave: Daseinsanalyse; Terapia de grupo; Medard Boss.

\begin{abstract}
In 1965, Medard Boss publishes a book based on his travels to India and Indonesia, which happened a decade earlier. Invited as a visiting professor of medicine, he accompanies the westernization of Indian medicine, which gives him the chance to reflect about the limitations of western thinking about human being, as well as to consider the possibility of understanding psychopathologic phenomena based on India's millennial 'ontology'. Is this travel journal he makes a brief consideration about group psychotherapies coordinated by Indian psychiatrists. On this article we present the translation to Portuguese of the two paragraphs about group therapy, which are almost the only ones ever written by Boss about this theme. Loyal to the psychoanalytic understanding of the psychotherapeutic phenomena, from which he never meant to distance himself, Boss interprets the group phenomena as transference and resistance. By doing this, he stresses the relationship of each participant of the group with the therapist, but pushes into the background other group phenomena.
\end{abstract}

Keywords: Daseinsanalysis; Group therapy; Medard Boss.

Resumen: En 1965, Medard Boss publica un libro basado en sus viajes a India e Indonesia en la década anterior. Invitado como profesor visitante de medicina, se pone en contacto con la occidentalización de la medicina india, que proporciona datos para reflexionar sobre las limitaciones del pensamiento occidental para la comprensión del ser humano, así como considerar la posibilidad de entender la psicopatología desde la milenar "ontología" de India. En este informe de viaje, considera brevemente los grupos de psicoterapia coordinados por psiquiatras indios. En este artículo se presenta una traducción de dos párrafos sobre la psicoterapia de grupo, que son casi los únicos escritos por Boss sobre el tema en toda su obra. Fiel a la comprensión psicoanalítica de la psicoterapia fenómenos, que nunca quiso alejarse, Boss interpreta los fenómenos grupales como transferencia y resistencia. Con esto subraya la relación de cada participante con el terapeuta del grupo, relegando a un segundo plano otros fenómenos grupales.

Palabras-clave: Daseinsanalyse; Terapia de grupo; Medard Boss.

O mundo do Dasein é mundo compartilhado. (Heidegger, Ser e Tempo, §26)

Medard Boss, psiquiatra suíço nascido em 1903, é conhecido como o fundador da Daseinsanalyse, uma nova ciência voltada para a compreensão do homem e de modos de intervenção e cuidado condizentes com a especificidade de seu ser. A descrição da existência humana que fundamenta sua obra é aquela desenvolvida pelo fi- lósofo Martin Heidegger, principalmente no livro Ser e Tempo (Heidegger, 1927/1998). Boss assume a tarefa de desenvolver uma disciplina que demonstre "os fenômenos existenciais comprováveis do Dasein social-histórico e individual relacionados no sentido de uma antropologia ôntica, de cunho daseinsanalítico" (Boss \& Heidegger, 1987/2009, p. 164-5), dividida em uma antropologia daseinsanalítica da existência saudável e uma patologia compreendida à luz do homem como Dasein, ser-aí. Para 
cumprir essa tarefa, Boss recebe a ajuda do filósofo, que durante dez anos frequenta sua casa em Zollikon, lecionando para médicos psiquiatras em seminários em que tematiza a condição humana à luz da analítica existencial, visando à construção dessa ciência humana livre dos pressupostos científico-naturais deterministas que obscurecem a compreensão dos processos de cura (Boss \& Heidegger, 1987/2009).

Apesar de pouco conhecida, a obra de Boss é reconhecida internacionalmente. Em 1951 é eleito Presidente da Sociedade de Medicina Suíça, permanecendo no cargo até 1958, e em 1954, presidente da Federação Internacional de Psicoterapia Médica até 1967, além de receber convites de universidades nas Américas e na Ásia para apresentar o trabalho que estava desenvolvendo. É convidado para lecionar em universidades em Lucknow, Delhi e Bangalore entre 1956 e 1959 e publica um relato dessas viagens e de suas descobertas já em 1959. Na Índia, assim como na Indonésia, Boss entra em contato com modos de vida e filosofias orientais, que repercutem na sua compreensão do adoecimento humano. Nesses lugares, entretanto, é convidado para lecionar sobre práticas de cura ocidentais, levando seu conhecimento médico e psicológico a esses povos que rapidamente se ocidentalizavam (Boss, 1959/1965).

Além de conhecimentos sobre a medicina ocidental, Boss conhece profundamente a psicanálise. Em 1925 muda-se para Viena, onde inicia sua análise didática com Freud. Forma-se médico em 1928 pela Universidade de Zurique e assume o posto de assistente de Eugen Bleuler, com quem aprofunda a interpretação psicanalítica dos fenômenos psicopatológicos estudados na Clínica Psiquiátrica Burgholzli. É nessa mesma clínica que entra em contato com o pensamento fenomenológico dos psiquiatras Jaspers, Minkowski e Binswanger, iniciando sua crítica à metapsicologia freudiana, que ele considera restritiva para a compreensão dos fenômenos encontrados no processo psicanalítico, que ele investiga tanto nas clínicas psiquiátricas em que trabalha quanto em seu consultório particular, inaugurado em Zurique em 1935 (Stern, 1979/1994).

Boss elogia e critica a psicanálise simultaneamente. Ele é profundamente elogioso das descobertas de Freud sobre o processo de libertação do sofrimento 'psicológico’ pela psicanálise. Considera que Freud descobriu na sua experiência clínica que os fenômenos humanos são dotados de sentido, isto é, são atos intencionais cujo significado pode ser compreendido à luz da totalidade da vida do paciente. A descoberta desse sentido depende da fala que, na compreensão que Boss desenvolve a partir da analítica existencial, é condição humana. Assim, o daseinsanalista encontra na psicanálise freudiana indícios da existência. Esses indícios, entretanto, são encobertos por hipóteses explicativas que fornecem causas para os comportamentos manifestos, num esforço de corresponder à exigência científico-natural de encadeamentos cau- sais. A Daseinsanalyse de Boss é o encontro da psicanálise freudiana com a analítica existencial heideggeriana. Ele entende que, por ficar preso ao modelo científico natural, Freud viu-se obrigado a formular um aparelho psíquico movido por uma "energia” psíquica, explicando os fenômenos mentais de acordo com as leis físicas (Boss, 1984/1997; Evangelista, 2004)

A fenomenologia de Heidegger é um método de "deixar e fazer ver por si mesmo aquilo que se mostra, tal como se mostra a partir de si mesmo" (Heidegger, 1927/1998, p. 57). Ele desenvolve essa compreensão deixando claro que "o sentido específico do logos, só poderá ser estabelecido a partir da 'própria coisa' que deve ser descrita, ou seja, só poderá ser determinado cientificamente segundo o modo em que os fenômenos vêm ao encontro" (Heidegger, 1927/1998, p. 57). É por fidelidade a este princípio fenomenológico que Boss dedica sua vida à elaboração de uma "terapia amparada numa fundamentação mais humana e mais em conformidade com o Dasein (Daseinsgemäss) da medicina” (Boss, 1994, p. xxx), livre dos pressupostos que obscurecem a compreensão da existência e que a aprisionam, tal como a metapsicologia freudiana na perspectiva do daseinsanalista.

A necessidade do método fenomenológico advém exatamente do modo de ser dos fenômenos, que se desvelam ao Dasein sempre à luz dos mundos compartilhados em que existe. Na existência cotidiana são compartilhados significados tradicionais; isto é, interpretações do que são e como são os fenômenos. A tradição, entretanto, pode encobrir modos de ser dos fenômenos (Heidegger, 1927/1998). Será que a psicanálise freudiana, na condição de tradição e de setor ôntico (Heidegger, 1927/1998), tem traços encobridores para Medard Boss? Isto é, será que a psicanálise delimita um modo de acesso aos fenômenos da psicoterapia para o fundador da Daseinsanalyse?

Caso a resposta seja afirmativa, isso não seria considerado um erro ou deficiência de sua obra. Muito pelo contrário, Medard Boss faz questão de não ser considerado um dissidente da psicanálise freudiana. Afirma que:

Certa vez Freud afirmou definitivamente que estava disposto a conceder o direito de classificar como Psicanálise qualquer método psicoterapêutico que reconheça a 'transferência' e a 'resistência' como partes essenciais. Portanto, não preciso me ver como um dissidente de Freud, considerando a prática de meu tratamento das neuroses e das perversões. (Boss, 1947/1949, p. xiii)

Sua obra é de grande valor para a psicologia e merece mais visibilidade do que tem atualmente. Infelizmente, no Brasil, a Daseinsanalyse foi agrupada na categoria das Psicologias Humanistas (Feijoó, 2011) e sua especificidade, desconsiderada. 


\section{Psicanálise dos grupos}

O início da Daseinsanalyse é marcado pelo diálogo com a psicanálise freudiana, mas logo Boss vê a necessidade de situar-se em relação a outras abordagens psicoterapêuticas que dialogam com a Filosofia. Tenta demarcar a diferença entre a ciência que desenvolve da psicanálise existencial de Sartre e de psiquiatrias antropológicas, como as de Erwin Straus, Emil Gebsattel e Ludwig Binswanger, dialogando com as mesmas (Boss, 1947/1949). Mas com a crescente influência do pensamento de Heidegger, sua reflexão abarca novas questões psicológicas ligadas à sua época, principalmente a falta de sentido do homem moderno. A neurose do tédio (ou do vazio) "é a forma de neurose do futuro imediato" (Boss, 1977, p. 17), proclama em 1961, que corresponde à existência do homem moderno, caracterizada pela "alienação em si-mesmo dos homens da atual sociedade industrial" (Boss, 1977, p. 57). Heidegger pensa sua época atual como Era da Técnica, e suas reflexões, em algum grau, influenciam Medard Boss (Feijoó, 2011). Essa época em que Boss busca novos fundamentos - mais correspondentes ao ser humano - é também marcada pelo isolamento do homem, por sua crença no autocontrole e na autodeterminação e na expectativa de meios técnico-científicos para a resolução de quaisquer problemas. A psicoterapia de grupo poderia ser uma alternativa neste quadro, dado que é um processo psicológico que ocorre na convivência com outras pessoas. Embora não possa ser interpretada como uma técnica para "tratar" a solidão do homem moderno, pode, sim, contribuir. Essa é uma perspectiva apontada por Camasmie (2012), cuja tese de doutorado é trabalho pioneiro na tematização da psicoterapia de grupo numa perspectiva fenomenológico-existencial no Brasil.

O método psicanalítico descrito por Freud surgiu e se desenvolveu tematizando a relação dual analista-paciente. Mas ainda no início do desenvolvimento da psicanálise surgem propostas de atendimentos em grupo. A expressão "psicoterapia de grupo" foi utilizado pela primeira vez por Jacob Moreno, que foi estudante de medicina em Viena e conheceu Freud, mas rejeitou o modelo psicanalítico em prol do que foi se desenvolvendo sob o nome de Psicodrama, uma prática psicoterapêutica que, em sua origem, só se realizava em grupos (Osório, 2003; Calderoni \& Bassani, 2010). Mas o Psicodrama não é a única nem a última abordagem psicoterapêutica grupal na história da psicologia. Práticas psicológicas grupais surgem fundamentadas nas psicologias correntes, assim como erigem novas psicologias. Há grupos de encontro fundamentados em Carl Rogers (1970/1974), grupos na Gestalt-terapia, grupos psicanalíticos, grupos operativos (Osório, 2003). Até o momento, entretanto, não apareceu nenhuma tentativa de fundamentar uma psicoterapia de grupo daseinsanalítica. O mais próximo disso é a reflexão de Calderoni \& Bassani (2010), aproximando
Psicodrama e Daseinsanalyse, e a recente tese de doutorado de Camasmie (2012), que busca fundamentos filosóficos heideggerianos, mas passa ao largo da obra de Medard Boss. Os estudos que refletem sobre a psicoterapia de grupo frequentemente o fazem em comparação à psicoterapia individual. Isso situa a psicoterapia de grupo num "lugar instável nas práticas clínicas" (Camasmie, 2012, p. 1); pouco reconhecida por sua especificidade, ela é medida por sua eficiência em relação aos processos individuais, principalmente pela quantidade de pacientes que podem ser atendidos ao mesmo tempo ${ }^{1}$. Será que o modelo psicoterapêutico daseinsanalítico não permite tal prática?

Freud desde muito cedo na história da psicanálise teoriza sobre a relação dos homens em grupos e comunidades. Em 1913 publica Totem e Tabu (Freud, 1913/2013), reunião de ensaios nos quais debate com a psicologia social. Nesse livro, recorre aos relatos da antropologia de organizações sociais de povos primitivos para discutir a formação de laços comunitários, comparando-os aos comportamentos de pacientes neuróticos. Por exemplo, a relação de um povo com seu líder é caracterizada como ambivalente; a figura do líder (rei, sacerdote, governante, etc.) incita nos demais o desejo de realizar um ato proibido - o tabu - mas, por isso, ele é detestado. O líder é, assim, amado e odiado concomitantemente. Os rituais que o cercam restringem seus comportamentos, punindo-o por seu poder. Um dos dois tabus fundamentais nessas comunidades primitivas é a proibição de matar o 'totem' - seja ele animal ou coisa - estendida ao líder. A transgressão do tabu resultaria, hipotetiza Freud (1913/2013), na dissolução da comunidade. O segundo tabu onipresente nessas comunidades refere-se a relações sexuais com membros do mesmo clã (ou família). A moralidade humana, enquanto reguladora das relações sociais, funda-se com a proibição do incesto e do parricídio; isto é, com o complexo de Édipo.

Freud não praticou nem recomendou que suas teorias fossem usadas para psicoterapia de grupo. Mas elas fundamentam a compreensão dos processos grupais que surgem sob influência da metapsicologia (Osório, 2003). Por exemplo, o tabu em relação a governantes (Freud, 1913/2013) pode ser claramente transposto para a interpretação da relação dos participantes de uma psicoterapia de grupo com o analista. Aqueles nutrem pelo analista sentimentos ambivalentes; atribuem a ele o poder curativo, mas temem seu poder. Sentem por ele afeição e hostilidade, tal como uma criança por seu pai. Segundo Freud, "a imagem que um filho faz do pai é habitualmente investida de poderes excessivos desta espécie e descobre-se que a desconfiança do pai está intimamente ligada à admiração por ele" (Freud, 1913/2013). Mas a

\footnotetext{
Por isso, a psicoterapia de grupo no Brasil acaba sendo vista como atendimento oferecido em instituições e pelo serviço público de saúde, em oposição à psicoterapia individual realizada em consultórios particulares.
} 
hostilidade para com o analista é proibida, reprimida, tabu. Essa compreensão sofre poucas alterações ao longo da obra freudiana, de modo que, quando a psicanálise é aplicada à psicoterapia de grupos, o complexo de Édipo permanece sendo a matriz de interpretação dos fenômenos grupais. Nessa concepção, os participantes dos grupos nutrem entre si sentimentos fraternais de rivalidade. O cerne da psicanálise de grupos é a relação transferencial de cada participante com o analista, com quem revive suas neuroses infantis, seus sentimentos de amor e ódio. Desta maneira, pode-se afirmar que cada paciente é tratado individualmente no grupo.

Como estudioso da obra de Freud, Boss conhece os estudos de Freud sobre grupos. Porém, o daseinsanalista escreve muito pouco sobre terapia de grupo ao longo de sua obra. Será que conhece outros intérpretes da psicanálise, que levaram as propostas de Freud para o contexto grupal? Conhece o trabalho de outros psicólogos contemporâneos seus, como Wilfred Bion, Fritz Perls, Enrique Pichon-Rivière, Carl Rogers, que desenvolveram modelos de psicoterapia de grupo? Esta pergunta fica guardada para outro estudo. Neste momento, o foco é a compreensão que Boss tem da psicoterapia de grupo.

Pesquisando seus escritos, até o momento encontrei apenas duas brevíssimas menções a atendimentos em grupo. A primeira é um comentário feito por Heidegger em 1966, num seminário em Zollikon; o filósofo diz aos participantes que numa conversa particular, Boss compara os seminários com um processo de terapia de grupo "que possibilitaria uma visão mais livre, um deixar ver mais adequado da constituição humana. No decorrer de tal terapia de grupo surgiriam, como numa análise freudiana, resistências que se dirigiriam contra a libertação. As resistências contra o tratamento heideggeriano (...)" (Boss \& Heidegger, 1987/2009, p. 173).

O segundo comentário que encontrei é o que traduzo abaixo. Tomando-o como referência, tento depreender uma compreensão da psicoterapia de grupo.

\section{Daseinsanálise de Grupo?}

Boss (1959/1965) publica um relato de suas viagens à Índia e à Indonésia entre 1956 e 1959 sob o título Indienfahrt eines Psychiaters ${ }^{2}$. O psiquiatra é convidado em 1955 pelo diretor da Escola de Medicina da Universidade de Jacarta e logo depois pelo Centro Psiquiátrico da Universidade de Lucknow, no norte da Índia, para um período como professor visitante. Boss responde afirmativamente a esses convites, considerando a possibilidade de se aproximar do pensamento oriental, que ele já estudava há 10 anos, quando participava de grupos de estudo semanais com Jung.

\footnotetext{
2 Traduzido para o inglês em 1965 (Boss, 1959/1965) e para o francês em 1971 (Boss, 1959/1971). Para o presente artigo, foram usadas ambas as traduções.
}

Em Lucknow, em 1959, Boss encontra o rápido crescimento de centros médicos como modo de responder à demanda por médicos para a população, sobretudo após a recente independência em relação à Inglaterra (ocorrida em 1947). O serviço de saúde público do país precisa rapidamente se desenvolver. Para isso, são criados um centro de treinamento médico central e as universidades em cada estado recebem verba para se especializar cada uma num ramo da medicina, de modo a dispor de todas as especialidades médicas e a poder formar futuros médicos em todas elas (Boss, 1959/1965). Esses centros e as especialidades médicas recebem influência direta da medicina europeia, encontrando estudantes maravilhados com os métodos de pesquisa e os resultados das intervenções ocidentais, o que também acirrou os ânimos de defensores da tradição milenar da medicina ayurvédica. O convite a Boss, então presidente da Federação Internacional de Psicoterapia Médica, é, portanto, para que ensine aos médicos indianos a psicoterapia ocidental, o que ele realiza através de atendimentos, seminários e supervisões clínicas.

Como médico e psicoterapeuta convidado, Boss supervisiona sessões de psicoterapia de grupo didática aos psicoterapeutas indianos em treinamento. Ele se refere a essa experiência no seu relato com o objetivo de considerar a semelhança do sofrimento humano no oriente e no ocidente, mostrando que o objetivo da psicoterapia é lidar com o sofrimento humano. Nessa reflexão, então, mostra que a psicoterapia em grupo com participantes indianos apresenta fenômenos similares aos que encontrava na Europa. Vejamos seu comentário sobre estes grupos:

Por exemplo, no caso de psicoterapia realizada para fins de treinamento com uma dúzia de estudantes saudáveis de psicologia e medicina, ao longo dos muitos meses de tratamento apareceram primeiramente uma competição por status mais ou menos contida dentro do grupo, assim como ocorre entre pessoas do Ocidente. Depois apareceram problemas de autoridade em relação ao líder do grupo com cada um dos participantes, repetindo as experiências de vida formativas que tiveram com pais e cuidadores; cada um reagindo diferentemente de acordo com suas particularidades. Novamente aqui, os fenômenos correspondem exatamente ao que esperaríamos encontrar no Ocidente. Em uma pessoa imediatamente, em outra, logo depois apareceram os fenômenos costumeiros de resistência, o desejo de se abster, o mau humor, o secamento de memórias dos sonhos, críticas aos outros membros do grupo e ao médico responsável. Estes são os mesmos fenômenos que regularmente brotam no ocidente. Eles são os sintomas de defesa contra a tomada de consciência de tendências até agora repelidas, dificilmente compatíveis com a autossuficiência e com as concepções morais. A compreensão destas reações como evasões e a superação das mesmas, a sinceridade consigo mesmo tornada assim 
possível e o aprender a assumir-se responsavelmente correspondem de todas as maneiras a observações correntes no Ocidente, tanto em terapias de grupo quanto no curso de todas as psicanálises individuais. Novamente, assim como no Ocidente, mostraram-se serem os fatores curativos mais importantes e decisivos. Nos seres saudáveis, foram capazes de liberar ainda mais energia criativa, enquanto nos seres doentes levaram à dissolução dos sintomas.

Dentre os participantes doentes de outro grupo havia um paciente esquizofrênico, que fora submetido a uma operação "psicocirúrgica". Devido à eliminação cirúrgica dos lobos frontais, ele foi bastante desumanizado. Já na primeira hora desta terapia de grupo, este paciente contou aos companheiros que era preguiçoso demais para fazer qualquer coisa além de comer e dormir. Embora tenha feito essa afirmação com bastante calma, sua fala deixou os demais muito excitados. Para eles, que nada sabiam sobre a operação, era muito perturbante e alarmante que um ser humano conseguisse afundar a um nível tão baixo de existência. Todos eles tentaram insistentemente descobrir se ele não tinha, afinal, nenhum tipo de interesse ou objetivo futuro na vida. Eles, então, se sentiram bastante aliviados ao descobrirem que a própria participação dele nas sessões terapêuticas grupais já denunciava a vontade de tornar-se saudável. Mas eu já havia observado uma vez no Ocidente exatamente a mesma reação numa sessão de psicoterapia de grupo. Lá também a indignação geral com a desumanização de um participante leucotomizado foi ainda maior do que o mal-estar causado pela confusão psicótica e pela violência do mesmo paciente antes da operação (Boss, 1959/1965, p. 59).

Portanto, nesta rápida comparação entre a psicoterapia de grupo conduzida na Índia e no Ocidente, Boss revela uma compreensão sobre alguns fenômenos "costumeiramente" encontrados nessa modalidade de tratamento. Menciona: 1) competição por status no grupo, 2) problemas de autoridade com o líder, 3) repetição das experiências de vida formativas com pais e cuidadores, 4) resistência, 5) sintomas de defesa e 6) compreensão e superação das resistências como fatores curativos, apontando isto como o sentido do processo psicoterapêutico tanto individual quanto de grupo.

Passemos então à explicitação destes fenômenos, considerando a compreensão que os fundamenta.

\section{Explicitação dos fundamentos da compreensão bossiana dos fenômenos grupais}

A obra de Medard Boss é dedicada à elaboração de uma psicologia e uma medicina mais pertinentes ao existir humano. Ele encontra na analítica do Dasein uma compreensão sobre o humano e seus modos de ser livres dos pressupostos científico-naturais até então usados para explicar o adoecer humano e os processos de cura. Com base na analítica do Dasein, formula compreensões mais bem fundamentadas do que “(...) as 'estrênuas acrobacias mentais' impostas pela psicanálise em ambos o analista e o analisando" (Boss, 1994, p. xii), fundando uma ciência "mais 'objetiva' e mais 'científica' do que as ciências do comportamento" (Boss, 1963, p. 29), pois possibilita um entendimento livre de hipóteses sobre o que é um processo psicoterapêutico. É esse interesse científico que o leva também a propor o abandono de alguns termos psicanalíticos, pois, fiel ao método fenomenológico, reconhece que "entrincheirados por trás das palavras validadas por uma orientação conceitual particular estão seus prejuízos secretos." (Boss, 1994, p. 125) Essa compreensão Boss retoma de Ser e Tempo, onde Heidegger explica que:

(...) o Dasein não tem somente a tendência de de-cair no mundo em que é e está, e de interpretar a si mesmo pela luz que dele emana. Juntamente com isso, o Dasein também de-cai em sua tradição, apreendida de modo mais ou menos explícito. A tradição lhe retira a capacidade de se guiar por si mesmo, de questionar e escolher a si mesmo. (...) A tradição assim predominante tende a tornar tão pouco acessível o que ela 'lega' que, na maioria das vezes e em primeira aproximação, o encobre e esconde (Heidegger, 1927/1998, p. 49).

Assim como a obra de Heidegger lhe é referência, a psicanálise apresenta-lhe uma prática psicológica voltada para a libertação de amarras, que impedem o deixar-ser dos fenômenos no mundo do paciente. E a obra freudiana lhe é tão próxima quanto a ontologia hermenêutica de Heidegger. Boss deixa claro que o seu esforço é fornecer uma fundamentação mais adequada aos fenômenos descobertos por Freud e, como já mencionado acima, ele faz questão de não ser considerado um dissidente da psicanálise de Freud.

Como estudioso da obra freudiana, Boss certamente conhece os escritos de Freud sobre grupos e conhece as interpretações psicanalíticas, que partem do pressuposto enunciado acima de que as experiências infantis com as figuras parentais são formadoras dos conflitos revividos no setting analítico. No livro que reúne sua contribuição à medicina e à psicologia ele afirma que a relação médico-paciente, chamada de transferência pela psicanálise, é "a base genuína de todas as formas de tratamento", "o verdadeiro lócus de todos os esforços terapêuticos" (Boss, 1994, p. 257). O conceito de transferência é criticado por Boss com base em seus pressupostos mecanicistas. Ele afirma:

É surpreendente que a teoria da transferência tenha tomado o lugar do pensamento médico tão rápida e 
profundamente, pois é óbvio o caráter fictício de suas suposições. Se as afeições são para ser deslocadas de alguma representação dentro da psique para fora, para objetos do mundo exterior, estas afeições endopsíquicas e representações deveriam primeiro existir. Mas, temos enfatizado repetitivamente que não há qualquer evidência nos fenômenos da existência humana que demonstre a presença de ambos (Boss, 1994, p. 267).

Por outro lado, reconhece que Freud descobriu um importante fenômeno da relação terapêutica. Quanto aos fenômenos encontrados na psicoterapia de grupo em Lucknow, não são os mesmos previamente delimitados pela teoria psicanalítica? Sua leitura do processo de terapia de grupo reconhece que os participantes da terapia de grupo revivem as experiências infantis de disputa pelo afeto dos pais, competindo entre si por status e brigando com a autoridade do coordenador, tal qual irmãos brigando entre si. De acordo com isso, aparece para Boss (1959/1965) a "competição por status mais ou menos contida dentro do grupo” (p. 59), que é manifestação da rivalidade 'fraternal' entre os participantes, todos desejosos do afeto do analista, que assume nesta situação o lugar de pai. Daí surge também a ambivalência afetiva com o analista, pois junto com o amor e a admiração, ele é visto como um obstáculo para a realização dos desejos de poder de cada participante. Ademais, o desejo de assumir seu lugar gera culpa. Essa é a explicação psicanalítica para os "problemas de autoridade em relação ao líder do grupo” (Boss, 1959/1965, p. 59) encontrados por Boss. Para a psicanálise, essa situação é a reencenação das relações afetivas infantis. Também são descobertas no grupo "experiências de vida formativas que tiveram com pais e cuidadores" (Boss, 1959/1965, p. 59).

Essas semelhanças chamam a atenção para a grande proximidade entre a Psicanálise e a Daseinsanalyse de Boss. A diferença está na compreensão que se desenvolve dos fenômenos. Para a Daseinsanálise, as experiências parentais também são formativas de modos de ser. Boss atribui vários modos de restrições neuróticas a experiências com os pais. A relação com as figuras parentais pode restringir a realização de possibilidades existenciais da criança, que, ao amadurecer, permanece restrita na possibilidade de lidar correspondentemente com determinados campos de fenômenos. Quando um paciente vivenciando tal restrição chega ao consultório, relacionar-se-á com o profissional a partir das possibilidades de que dispõe e que podem ser poucas, limitadas, restritas. Assim, ele não está 'transferindo' para o psicoterapeuta modos de ser com seus pais, mas está se relacionando com ele a partir de como lhe é possível. Boss explica isso:

O que pode parecer uma transferência neurótica é na realidade um Dasein humano cuja abertura foi substancialmente restrita através de um mau direcionamento dos pais no início da vida. Tal Dasein pode continuar na idade adulta a ser incapaz de perceber ou responder a outros adultos, exceto nos poucos modos restritos que os pais patogênicos tenham-lhe permitido durante a infância. Uma pessoa cuja existência foi assim restringida desde a infância, sem a ajuda da psicoterapia, irá passar a vida vendo nos adultos somente aquelas características que se ajustam à percepção limitada que lhe permitiram na infância. Entre outras coisas, isto significa que o terapeuta, como qualquer outro adulto, irá aparecer na mesma maneira original e infantil... (Boss, 1994, p. 268)

Assim, na situação da terapia de grupo, Boss reconhece os fenômenos já apontados pela psicanálise, mas não os interpreta como questões transferenciais, mas, sim, como modos possíveis, porém limitados, de ser-com-os-outros. A competição por status e os problemas com a autoridade são modos restritos de se relacionar que podem, a partir da psicoterapia, ser superados. A psicoterapia é o caminho para o desvelamento das proibições e expectativas que sustentam esses modos e que impedem a apropriação de novos modos de ser-no-mundo-com-outros, com vistas a superá-las. Mas esses modos podem aparecer nas relações com todos os participantes do grupo. Assim como no cotidiano há uma multiplicidade de modos possíveis de relações pessoais, também em grupo é possível viver essa multiplicidade.

O abandono de modos de se compreender e a abertura para novas possibilidades existenciais é uma tarefa árdua, que os pacientes raramente assumem livremente, mesmo sofrendo com suas restrições. Frequentemente, portanto, aparecem os "fenômenos costumeiros de resistência” (Boss, 1959/1965, p. 59), assim como "sintomas de defesa contra a tomada de consciência de tendências até agora repelidas" (Boss, 1959/1965, p. 59), encontradas por Boss nos grupos. Mas nesse apontamento revela-se outra semelhança entre seu modo e o modo psicanalítico de interpretação de fenômenos grupais. Os fenômenos de resistência aparecem na relação médico-paciente. Boss é enfático na afirmação de que Freud é descobridor também desses fenômenos característicos dessa relação, mas fica restrito na possibilidade de compreendê-los. Resistência é o estar-fechado e sem liberdade para se apropriar de e corresponder a possibilidades existenciais, impedindo a relação aberta com os entes que aí se manifestam. Frequentemente referem-se a proibições a experimentar ser possibilidades existenciais que se anunciam, devido a elas terem sido na biografia do paciente interpretadas como erradas e pecaminosas. Mesmo na situação terapêutica os pacientes não permitem que se manifestem por as julgarem desagradáveis, indiscretas, irrelevantes ou banais.

A superação da resistência e a apropriação de novos modos de ser é possível a partir da relação médico-pa- 
ciente. Esta relação, que é chamada pela Psicanálise de transferência, é uma relação humana e precisa ser considerada enquanto tal. Isso significa que os sentimentos que o paciente tem pelo psicoterapeuta, ele realmente os tem pelo psicoterapeuta; igualmente, os sentimentos que pode ter pelos demais participantes de um grupo são, realmente, em relação a eles. Esta é a principal divergência da Daseinsanalyse com a Psicanálise; as relações médico-paciente não são distorções nem transferências de afetos destinados a outrem. Na relação terapêutica o paciente se relaciona com os outros tal como lhe é possível. Explica Feijoó (2011), que “a pessoa se encontra limitada e restrita em suas possibilidades. Portanto, percebe o analista ou o cônjuge com a mesma limitação com que olhava seu pai ou sua mãe. Não dispondo de novas possibilidades de relação, mantém o mesmo padrão de sua infância" (p. 33). Mas é exatamente no processo psicoterapêutico que os modos constituídos podem aparecer e novos modos de ser-com-os-outros podem surgir. Boss enfatiza a relação de cada participante com o analista do grupo, tal como aprendera com Freud.

Assim, a concepção de terapia de grupo de Boss está em sintonia com aquela que deriva da psicanálise: cada participante relaciona-se individualmente com o analista. Para ele, o objetivo da terapia individual e em grupo é o mesmo: a apropriação de possibilidades existenciais impedidas em função de restrições do Dasein, que se dá através do poder-compreender e superar as resistências que impedem o desenrolar do processo psicoterapêutico. Assim, não há uma distinção entre terapia de grupo e terapia individual. Mas, ao privilegiar a relação com o psicoterapeuta, relega a segundo plano as relações entre os participantes. Em decorrência, essas relações são compreendidas como competição por status e pela atenção da figura de autoridade.

Boss (1959/1965) nota que os pacientes do grupo ficam indignados com a desumanização do participante leucotomizado. Na sequência do comentário aos grupos, ele fala de curiosidade, excitação, estranhamento, perturbação e indignação diante do paciente lobotomizado. Não são esses modos de lidar fenômenos grupais que surgem das relações interpessoais entre os membros? Não podem esses fenômenos possibilitar aos pacientes o desvelamento e a apropriação de novos modos de ser-no-mundo-com-os-outros? Esses fenômenos brotam da interrelação dos participantes, que não é, necessariamente, uma rivalidade, uma 'transferência', nem uma resistência. Mas a ênfase dada por Boss à relação analista-analisando ocorre em detrimento da descoberta de que o grupo pode ser um espaço privilegiado para o surgimento de múltiplas relações interpessoais, assim como para o desvelamento de novos modos de ser-com-os-outros. Como lembra Camasmie (2012),

A clínica de grupo é uma modalidade de psicoterapia marcada principalmente pela experiência da convivência. É pela presença dessa característica constitutiva que os modos de ser-com-o-outro tendem a se tornar visíveis mais rapidamente do que outras modalidadespsicoterápicas (p. 45).

Embora Boss perceba isso, sua interpretação da psicoterapia de grupo permanece fiel à psicanálise freudiana, que concentra na relação com o analista o desenrolar do processo terapêutico.

\section{Considerações finais}

Fenomenologia é "deixar e fazer ver por si mesmo aquilo que se mostra, tal como se mostra a partir de si mesmo" (Heidegger, 1927/1998, p. 65). É essa atitude que fundamenta as pesquisas de Boss, comprometido a resgatar o homem e os tratamentos a ele destinados das abstrações científicas que os encobrem. É assim que Boss procede na Daseinsanalyse: fornecendo fundamentações mais correspondentes ao existir humano à medicina e à psicanálise. No âmbito psicoterapêutico, Boss parece partir de um campo de fenômenos já desvelados por Freud para fornecer-lhes a compreensão de que carecem. O mesmo pode ser dito da leitura bossiana dos processos grupais, só que, aqui, ele perde de vista outros fenômenos que podem surgir nesse modelo psicoterapêutico.

Boss era um psicoterapeuta individual. Não tinha, portanto, condição nem obrigação de conhecer a fundo os processos psicoterapêuticos em grupo. Desse modo, os questionamentos aqui levantados não são uma crítica a ele; são apenas uma tentativa de libertar os fenômenos da psicoterapia de grupos das delimitações fundadas pela tradição psicanalítica.

Será que a leitura fenomenológico-existencial dos fenômenos grupais revela que a psicoterapia de grupo é um processo psicoterapêutico individual conduzido em grupo? Esta é uma possibilidade aberta pela psicanálise, que entende que a problemática apresentada na situação de grupo é uma problemática individualizada, restrita à existência isolada de cada paciente e às relações com a família nuclear. Boss corrige a interpretação psicanalítica de que a relação com o terapeuta do grupo é a transferência de afetos ligados às figuras materna e paterna, mas mantém a noção de que modos imaturos de se relacionar provenientes da história de vida, sobretudo familiar, aparecem nessa relação, fomentando competição entre os demais participantes, admiração e competição com o coordenador e resistência para assumir as limitações e apropriar-se de novos modos de ser. Mas a seu ver, isso ocorre na relação terapeuta-paciente no grupo. Boss, assim como psicanálise, privilegia a relação de cada paciente com o terapeuta, trabalhando as questões de cada membro individualmente em grupo. Trata-se de uma extensão do modelo psicoterapêutico individual, que ele conhece tão bem, ao modelo grupal. 


\section{Referências}

Boss, M. (1949). Meaning and Content of Sexual Perversions: A Daseinsanalytic Approach to the Psychopathology of the Phenomenon of Love. Tradução de Liese Lewis Abell. New York: Grune \& Stratton (Original publicado 1947).

Boss, M. (1965) A Psychiatrist Discovers India. Tradução de Henry Frey. London: Oswald Wolff (Original publicado em 1959).

Boss, M. (1971). Un Psychiatre en Indie. Tradução de Rémi Laureillard. Paris: Fayard (Original publicado em 1959).

Boss, M. (1963) Psychoanalysis \& Daseinsanalysis. Tradução de Ludwig B. Lefebre. New York; London: Basic Books, Inc. Publishers.

Boss, M. (1997). Encontro com Boss. Daseinsanalyse - Revista da Associação Brasileira de Daseinsanalyse, 1, 2 e 4, 5-21(Original publicado em 1974).

Boss, M. (1997). Análise Existencial - Daseinsanalyse: Como a Daseinsanalyse entrou na Psiquiatria. Daseinsanalyse - Revista da Associação Brasileira de Daseinsanalyse, 22, 23-35 (Original publicado em 1975).

Boss, M. (1977). Angústia, Culpa e Libertação: Ensaios de Psicanálise Existencial. Tradução de Barbara Spanoudis. 2a. ed. São Paulo: Duas Cidades.

Boss, M. (1997). Introdução à Daseinsanalyse e Medicina Psicossomática: Ciência ou Magia? Daseinsanalyse - Revista da Associação Brasileira de Daseinsanalyse, 8, 17-29 (Original publicado em 1985).

Boss, M. (1994). Existential Foundations of Medicine \& Psychology. Northvale, New Jersey; London: James Aronson Inc.

Boss, M. (1997). Introdução à Daseinsanalyse. Daseinsanalyse - Revista da Associação Brasileira de Daseinsanalyse, 8 , 6-16 (Original de 1984).

Boss, M. \& Heidegger, M. (2009) Os Seminários de Zollikon Protocolos, Diálogos, Cartas. Tradução de Fátima Almeida Prado. Petrópolis, RJ: Vozes (Original publicado em 1987).

Calderoni, C. R. \& Bassani, M. (2010). Psicodrama e Daseinsanalyse: compatibilidades. Lins, SP: Raízes Gráfica e Editora.

Camasmie, A. T. (2012). Psicoterapia de grupo na abordagem fenomenológico-existencial: Contribuições heideggerianas. Doutorado em Psicologia. Universidade Federal Fluminense (UFF), Rio de Janeiro.

Evangelista, P. (2004) A Recepção do Inconsciente Freudiano da Daseinsanalyse de Medard Boss. Daseinsanalyse - Revista da Associação Brasileira de Daseinsanalyse, 13, 21-49.

Feijoó, A. A. (2011). Clínica Daseinsanalítica: Considerações Preliminares. Revista da Abordagem Gestáltica, 17(1), 30-36.

Freud, S. (2013) Totem e Tabu e outros trabalhos. Freud Online. Vol. XIII da Edição Standard das Obras Completas Disponível em http://www.freudonline.com.br/livros/ volume-13/vol-xiii-3-ii-tabu-e-ambivalencia-emocional/ Acessado em 27/06/2013 (Original de 1913).
Heidegger, M. (1998). Ser e Tempo. Petrópolis: Vozes (Original publicado em 1927).

Osório, L. C. (2003). Psicologia Grupal: Uma nova disciplina para o advento de uma era. Porto Alegre: Artmed.

Rogers, C. (1974) Grupos de Encontro. Tradução de Joaquim Proença. Lisboa: Livraria Martins Fontes (Original publicado em 1970).

Stern, P. (1994). Introduction to the English Translation. In: Medard Boss, Existential Foundations of Medicine $\&$ Psychology. Tradução de S. \& Cleaves, A Conway. New Jersey/ London: Jason Aronson Inc (Original publicado em 1979).

Paulo Eduardo Rodrigues Alves Evangelista - Psicólogo e Mestre em Filosofia pela Pontifícia Universidade Católica de São Paulo (PUC-SP); Professor e Coordenador das disciplinas de Psicologias Humanistas e fenomenológicas na Universidade Paulista (UNIP-SP); Doutorando em Psicologia da Educação e do Desenvolvimento Humano na Universidade de São Paulo (USP), e Coordenador do Centro de Formação e Coordenação de Grupos em Fenomenologia. Endereço Institucional: Universidade Paulista - Instituto de Ciências Humanas: Rua Dr. Bacelar, 1212, Vila Clementino, São Paulo, SP, CEP 04026-002. E-mail: pauloeevangelista@gmail.com

Recebido em 12.01.13 Primeira Decisão Editorial em 26.05.13 Segunda Decisão Editorial em 03.07.13 Aceito em 26.11.13 